\title{
The improved cure fraction for esophageal cancer in Linzhou city
}

\author{
Shuzheng Liu', Lanwei Guo', Qiong Chen', Liang Yu², Bianyun Li², Xiaogin Cao ${ }^{1}$ and Xibin Sun ${ }^{1 *}$
}

\begin{abstract}
Background: Survival of esophageal cancer in Linzhou was seen to increase over the past few decades and is higher than the average level of China due to the implementation of comprehensive prevention and control measures. In population-based studies, relative survival is a common index to approximate disease-specific survival. However, the cure fraction maybe great interest to patients and physicians. This study aimed to investigate the cure fraction of esophageal cancer in Linzou city during 2003-2012 with a cure model.

Methods: We carried out a population-based study of 8067 esophageal cancer patients in the Linzhou city during 2003-2012. Flexible parametric cure models were used to estimate cure proportions and median survival times of uncured by year of diagnosed and age. In each model, an interaction between calendar year and age were included. All variables in the model were included both as constant and time-varying effects.

Results: The 5-year relative survival rate was increased in every age group from 2003 to 2012. The huge increase in the cure proportion was observed in each age group. At the year of 2011-2012, 79.8\%, 58.0\%, 123.4\% and 162.7\% improvements of cure proportion were seen in age group 19-49, 50-59, 60-69 and 70-99 years compared with year of 2003-2004. Meanwhile, survival of 'uncured' patients changed little in all age group.

Conclusions: The improvement of survival in Linzhou city during 2003-2012 was mainly due to an increasing cure proportion. Huge improvement of cure fraction within short period is likely due to the organized screening of esophageal cancer in Linzhou city.
\end{abstract}

Keywords: Esophageal cancer, Survival analysis, Cure model

\section{Background}

Esophageal cancer is the eighth most common cancer around the world and the fifth most common cancer in China $[1,2]$. There is a large geographical variation with an incidence rate roughly 3 times higher in the incidence rates in low urbanization areas than high urbanization areas in China [3]. Linzhou city has high incidence of esophageal cancer in China. An organized screening of esophageal cancer in population was carried out since 2005. Survival of esophageal cancer in Linzhou was seen to increase over the past few decades and was higher than the average level of China [4-6]. Population-based studies of esophageal cancer survival are meaningful for clinicians, patients and health administrators.

\footnotetext{
* Correspondence: xbsun21@sina.com

${ }^{1}$ Henan Cancer Research and Control Office, Affiliated Tumor Hospital of Zhengzhou University, Henan Tumor Hospital, Zhengzhou 450008, China Full list of author information is available at the end of the article
}

In the population-based cancer registries, the survival for patients is traditionally measured using the cumulative survival function (cause-specific survival or relative survival) $[7,8]$. However, for patients and physicians, the cure fraction may be of great interest. Cure models can be used to calculate both the cure proportion and the survival function of "uncured" patients [9]. When looking at temporal changes, more detailed view of the changes observed in the survival of cancer patients can be obtained with cure model than traditional methods.

We study the survival of patients of esophageal cancer in Linzhou city from 2003 to 2012, using cure model.

\section{Methods \\ Data}

Data were extracted from the database of Linzhou Cancer Registry. The data of incidence of esophageal cancer was routinely linked to the database of vital statistic 
system to obtain date and cause of death information. Those unmatched cancer patients will be followed up annually. We studied patients diagnosed as esophageal cancer in the period 2003-2012. And patients were excluded if the cancer incidence was only recorded on the information on death certificates. All patients were followed up until death, emigration or 31th December, 2016.

\section{Statistical methods}

The relative survival is used commonly in the studies of population-based cancer registry as the measure of cancer patient survival. Relative survival is calculated as the observed survival divided by the expected survival in the disease-free population. When using relative survival the information of death cause is not needed and relative survival captures mortality directly and indirectly.

In cure model the patients diagnosed with cancer can be divided into two groups: cured patients (statistical cure) and uncured patients. The cured patients have the same mortality rate with the people of the same age and sex in the general population. So the cured patients will not experience excess mortality due to the cancer. And the cure proportion is defined as the proportion of cured patients in all patients. The point of statistical cure happens when the curve of cumulative relative survival shows a plateau and the proportion at the point is defined as the estimated cure fraction. The concept of statistical cure is different from medical cure at an individual level and used at a grouped level. Cure models can be used to calculate the cure proportion of the cured patients and the survival function of the uncured patients.

\section{Modelling approach}

The flexible parametric cure model, a special case of a non-mixture cure model, was fitted in this study [1012]. And instead of using a specific parametric distribution, the shape of the survival distribution was modeled with restricted cubic spline [13]. The flexible parametric cure model has been seen to fit better than the mixture and non-mixture model $[9,10,14]$. For cure fraction and median survival of the uncured group, calendar years were modeled continuously using splines [15] or 5 calendar periods (2003-2004, 2005-2006, 2007-2008, 2009-2010, 2011-2012) and age was divided in four categories (19-49, 50-59, 60-69 and 70-99). In each model, an interaction between calendar year and age were included. And all variables in the model were included both as constant and time-varying effects. To assess the fit of the cure models, we compared the estimated relative survival from the flexible parametric cure model with empirical life table estimates of relative survival using the Ederer II method [16]. All analysis was performed with the command of stpm2 [17] in stata12.0.

\section{Results}

There were 8067 patients (56\% males and 44\% females) with esophageal cancer in this study. The average age at diagnosis was 62 years. The relative survival rate was $36.3 \%, 33.5 \%, 26.8 \%$ and $17.8 \%$ in age group $19-49,50-$ $59,60-69$ and 70-99 years respectively during 20032004. At the year of 2011-2012 the rate was severally $62.5 \%, 49.0 \%, 51.1$ and $41.7 \%$ and there was $72.2 \%$, $46.3 \%, 90.7 \%$ and $34.3 \%$ improvements respectively compared with year of 2003-2004. Demographic characteristics and survival indicator were shown in Table 1.

First, models were fitted by sex separately. The fitted curves of the estimated relative survival rate for male and female can be seen in Fig. 1. The empirical life table estimates calculated with the Ederer II method are also shown in the figure. It can be seen that the flexible parametric cure model fits the data well. After 5 years of follow-up the curves of relative survival rate tend to reach a plateau.

During 2003-2004 period, the cure proportion was $33.7 \%, 31.4 \%, 21.8 \%$ and $11.0 \%$ in age group $19-49,50-$ 59, 60-69 and 70-99 (Table 2, Fig. 2) and at the year of 2011-2012 the proportion was $60.6 \%, 49.6 \%, 48.7 \%$ and $28.9 \%$ separately. There was constant improvement of cure proportion with time going on in all age groups. At the year of 2011-2012, 79.8\%, 58.0\%, $123.4 \%$ and $162.7 \%$ improvements of cure proportion were seen in age group 19-49, 50-59, 60-69 and 70-99 years compared with year of 2003-2004.

At the same time, median survival of 'uncured' patients changed little during different period. There were separately $0.01,-0.03,0.06$ and 0.03 years difference in median survival time for age group 19-49, 50-59, 60-69 and 70-99 from 2003 to 2012 . The time at which $90 \%$ of the 'uncured' patients are dead, which is another indicator for measuring survival of the 'uncured' has little variation in every age group (Table 2, Fig. 3 ).

\section{Discussion}

The 5 year relative survival rate was increased in each age group from 2003 to 2012. The cure fraction has increased greatly over time for esophageal cancer in Linzhou city during 2003-2012 with very little variation of median survival of uncured group at the same time. The improvement in survival was mainly attribute to an increasing proportion of 'cured' patients.

When studying trends with cure models considering the cure fraction and the survival time of the uncured patients at the same time, better answer will be probably distinguished from many competing explanations [18]. Higher cure proportion and longer survival time of 
Table 1 Demographic features of patients diagnosed with esophageal cancer in Linzhou city 2003-2012

\begin{tabular}{|c|c|c|c|c|c|c|}
\hline Calendar period & $2003-2004$ & $2005-2006$ & $2007-2008$ & 2009-2010 & 2011-2012 & Total \\
\hline Total No. of cases (\%) & $1439(17.8)$ & $1435(17.8)$ & $1730(21.4)$ & $1740(21.6)$ & $1723(21.4)$ & $8067(100.0)$ \\
\hline \multicolumn{7}{|l|}{ Sex, n (\%) } \\
\hline Male & $814(17.9)$ & $783(17.2)$ & $1013(22.3)$ & $943(20.7)$ & 995 (21.9) & $4548(100.0)$ \\
\hline Female & $625(17.8)$ & $652(18.5)$ & $717(20.4)$ & $797(22.6)$ & $728(20.7)$ & $3519(100.0)$ \\
\hline \multicolumn{7}{|l|}{ Age groups, years; n (\%) } \\
\hline $19-49$ & $182(24.0)$ & $160(21.1)$ & $155(20.5)$ & $120(15.9)$ & $140(18.5)$ & $757(100.0)$ \\
\hline $50-59$ & $465(18.7)$ & $449(18.0)$ & $582(23.4)$ & $534(21.4)$ & $460(18.5)$ & $2490(100.0)$ \\
\hline $60-69$ & $408(15.7)$ & $431(16.6)$ & $533(20.5)$ & $593(22.8)$ & $634(24.4)$ & $2599(100.0)$ \\
\hline 70-99 & $384(17.3)$ & $395(17.8)$ & $460(20.7)$ & $493(22.2)$ & $489(22.0)$ & $2221(100.0)$ \\
\hline Median age at diagnosis & 62 & 61 & 61 & 62 & 63 & 62 \\
\hline \multicolumn{7}{|c|}{5 year Relative survival rate (\%) } \\
\hline $19-49$ & 36.3 & 38.7 & 50.9 & 51.4 & 62.5 & 46.5 \\
\hline $50-59$ & 33.5 & 39.1 & 43.9 & 41.4 & 49.0 & 41.6 \\
\hline $60-69$ & 26.8 & 28.7 & 32.7 & 42.9 & 51.1 & 37.7 \\
\hline 70-99 & 17.8 & 22.0 & 25.7 & 31.7 & 41.7 & 28.3 \\
\hline
\end{tabular}

uncured represents a general improvement. Higher cure proportion and shorter survival time of uncured represents a selective improvement: improvements in treatment enabled uncured patients with a longer survival time to be cured. Stable cure proportion and longer survival time of uncured might occur due to better palliative care or new diagnostic techniques introduced which can move up the diagnosed date but without affecting the date of death, that is, lead time bias. Higher cure proportion and unchanged survival time of uncured might occur following introduction of some diagnostic procedure, like screening, which included more patients who have no excess risk.
An organized screening of esophageal cancer was carried out for people aged 40-69 since 2005 in Linzhou city. From 2006 to 2012, 22,869 people took part in the screening of esophageal cancer [19]. There were higher proportion of early-stage esophageal cancer cases and 5 year survival rate of esophageal cancer in endoscopy screening group in Linzhou city [20, 21]. According to the screening procedure, local people aged 40-69 will be organized to screen with endoscope for esophageal cancer. The detected high-grade dysplasia and cancer of esophagus in the screening will be treated and the detected mid-grade dysplasia of esophagus will be checked 1 year later. So there should be some high-grade

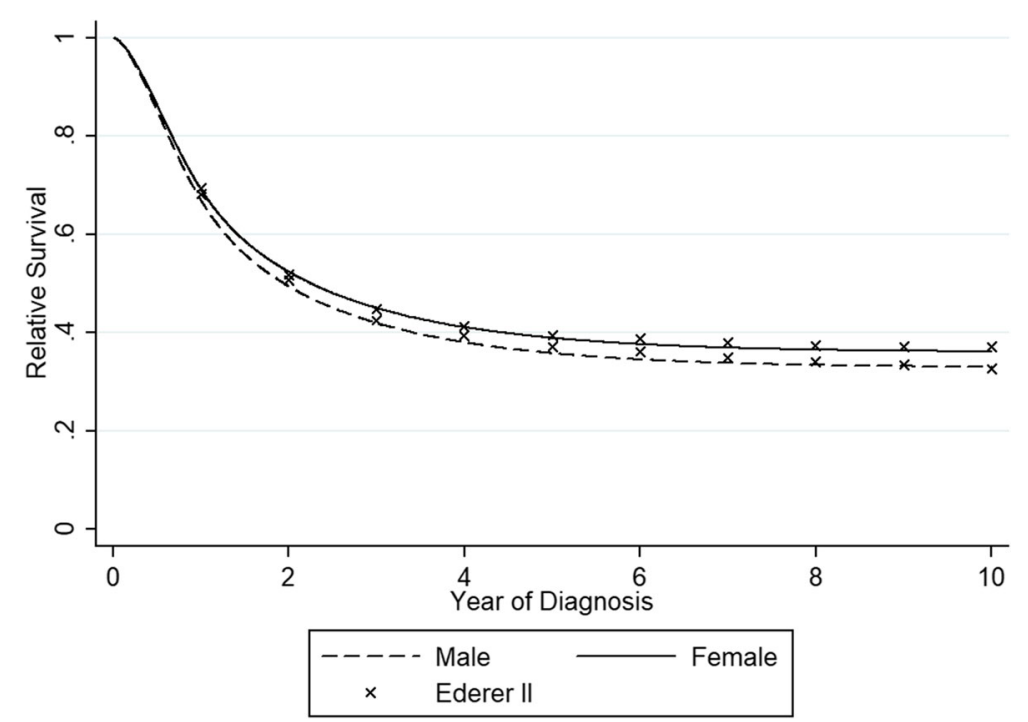

Fig. 1 Predicted relative survival by sex 
Table 2 Cure proportion(\%), median survival time of 'uncured' (years) and time at which 90\% of 'uncured' are dead (year), 95\% confidence intervals, for patients diagnosed with esophageal cancer in Linzhou city 2003-2012

\begin{tabular}{|c|c|c|c|c|}
\hline \multirow[t]{2}{*}{ Year } & \multicolumn{4}{|l|}{ Age group(years) } \\
\hline & $19-49$ & $50-59$ & $60-69$ & 70-99 \\
\hline \multicolumn{5}{|c|}{ Cure proportion (\%) } \\
\hline 2003-2004 & $33.7(27.0-40.5)$ & $31.4(27.2-35.7)$ & $21.8(17.9-26.0)$ & $11.0(8.0-14.4)$ \\
\hline $2005-2006$ & $34.4(27.4-41.6)$ & $38.1(33.5-42.7)$ & $25.7(21.5-30.0)$ & $14.6(11.0-18.5)$ \\
\hline $2007-2008$ & $49.6(41.5-57.2)$ & $42.2(38.0-46.3)$ & $31.8(27.7-36.0)$ & $18.1(14.4-22.1)$ \\
\hline 2009-2010 & $49.7(40.5-58.3)$ & $41.3(37.1-45.6)$ & $40.4(36.1-44.6)$ & $19.7(16.0-23.7)$ \\
\hline 2011-2012 & $60.6(51.6-68.4)$ & $49.6(44.7-54.4)$ & $48.7(44.3-52.9)$ & $28.9(24.3-33.6)$ \\
\hline \multicolumn{5}{|c|}{ Median survival of 'uncured' (years) } \\
\hline 2003-2004 & $1.14(1.01-1.27)$ & $1.19(1.10-1.27)$ & $1.02(0.94-1.10)$ & $0.75(0.68-0.81)$ \\
\hline 2005-2006 & $1.13(1.00-1.27)$ & $1.23(1.14-1.33)$ & $1.05(0.97-1.14)$ & $0.79(0.72-0.86)$ \\
\hline $2007-2008$ & $1.23(1.08-1.37)$ & $1.24(1.15-1.33)$ & $1.09(1.00-1.17)$ & $0.81(0.74-0.88)$ \\
\hline 2009-2010 & $1.28(1.13-1.43)$ & $1.28(1.19-1.38)$ & $1.21(1.12-1.30)$ & $0.86(0.79-0.93)$ \\
\hline 2011-2012 & $1.15(0.99-1.31)$ & $1.16(1.06-1.26)$ & $1.08(0.98-1.17)$ & $0.78(0.70-0.85)$ \\
\hline \multicolumn{5}{|c|}{ Time at which $90 \%$ of the 'uncured' are dead (years) } \\
\hline $2003-2004$ & $3.67(3.41-3.93)$ & $3.70(3.50-3.89)$ & $3.30(3.09-3.51)$ & $2.52(2.29-2.74)$ \\
\hline $2005-2006$ & $3.67(3.40-3.94)$ & $3.85(3.65-4.05)$ & $3.42(3.21-3.63)$ & $2.71(2.49-2.95)$ \\
\hline $2007-2008$ & $3.95(3.69-4.21)$ & $3.90(3.71-4.10)$ & $3.57(3.38-3.77)$ & $2.85(2.63-3.08)$ \\
\hline 2009-2010 & $4.02(3.76-4.28)$ & $3.95(3.76-4.14)$ & $3.85(3.65-4.04)$ & $3.00(2.78-3.22)$ \\
\hline 2011-2012 & $3.93(3.65-4.21)$ & $3.86(3.64-4.08)$ & $3.75(3.52-3.97)$ & $3.02(2.77-3.27)$ \\
\hline
\end{tabular}
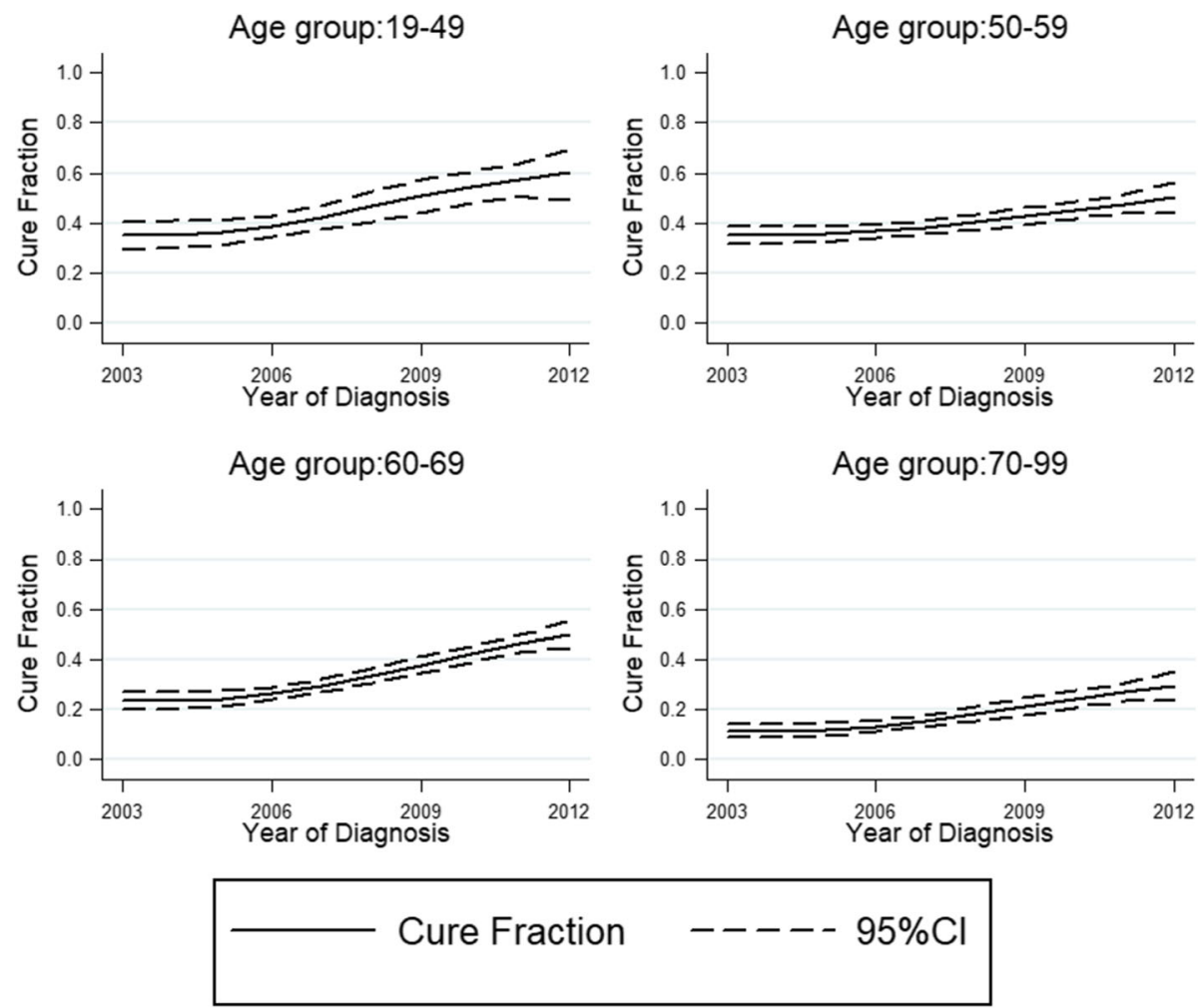

Fig. 2 Estimated cure fraction with 95\% confidence intervals presented by age group 


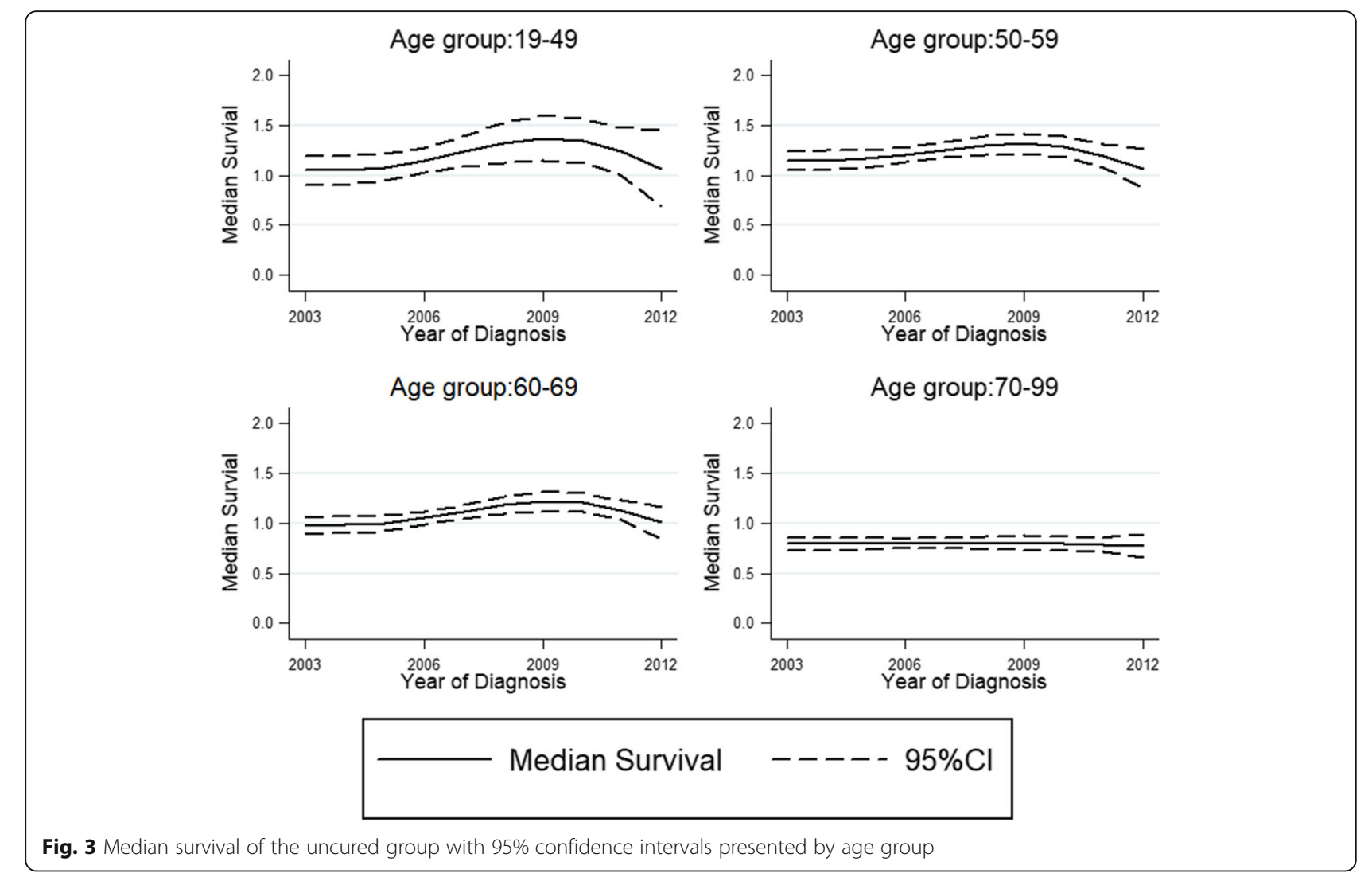

dysplasia or cancer of esophagus diagnosed by screening procedure in age group over 70 years. Hence the survival of esophageal cancer aged over 70 years can also be affected by the screening. An advantage of cure model is that the lead time bias has no effect on the cure fraction, so we can distinguish the true clinical benefit and lead time bias [18]. In this study, greatly improved cure fraction within short period showed a screening effect and a success in the screening of esophageal cancer in Linzhou city.

Although cure models have given us a better understanding of the survival of patients, we should keep in mind that there are some potential limitations. First, the model will still give the estimates of the cure fraction even when statistics cure is not reached. However, for esophageal cancer it seems not a problem. The cumulative relative survival for esophageal cancer was plateau after about 4 years from the date of diagnosis [4], indicating that the living patients at that time can be considered statistically cured. We have followed-up information at least 4 years which should be enough for reach a point of cure. Second, the traditional cure model may produce biased estimates in older age group due to less flexible to get the shape of the survival distribution [22]. However, the flexible parametric cure model has been shown to perform good even when older groups was included in the model [10]. In this paper, further study of cure fraction in different TNM stage cannot be done for the absence of stage variable in the data provided by Linzhou cancer registry which only collected the essential information of cancer registry during year 2003-2012.

\section{Conclusions}

Cure model analysis of cancer survival in China has not been reported ever. In this study, the flexible parametric cure model was used to analyze the survival of esophageal cancer in Linzhou city. And we found the improvement of survival in Linzhou city during 2003-2012 was mainly due to an increasing cure proportion. Huge improvement of cure fraction within short period is likely due to the organized screening of esophageal cancer in Linzhou city.

\section{Acknowledgements}

We thank the Linzhou Cancer Registry staff for extracting data from raw data sources and generating the dataset from the registry with permission for use.

\section{Availability of data and materials}

The anonymized datasets used and/or analyzed for the survival analysis in this study are available from the corresponding author on reasonable request.

\section{Authors' contributions}

All authors have made substantial contributions to the conception and design of the study. SZL led protocol design, statistical analysis, and manuscript drafting. LWG, QC, LY, BYL and XQC contributed to data quality control and interpretation. XBS contributed to revision of the manuscript. All authors have reviewed and approved the final version. 


\section{Ethics approval and consent to participate}

The dataset of the population-based cancer registry is registered as stipulated by the regulation of Methods of Cancer Registration Management according to National Health Commission of the People's Republic of China (www.nhfpc.gov.cn). All data collected in the database for the survival analysis were anonymous, and no ethical approval was required.

\section{Consent for publication}

Not applicable.

\section{Competing interests}

The authors declare that they have no competing interests.

\section{Publisher's Note}

Springer Nature remains neutral with regard to jurisdictional claims in published maps and institutional affiliations.

\section{Author details}

'Henan Cancer Research and Control Office, Affiliated Tumor Hospital of Zhengzhou University, Henan Tumor Hospital, Zhengzhou 450008, China.

¿Linzhou Cancer Registry, Linzhou Cancer Hospital, Linzhou 456500, China.

Received: 28 August 2017 Accepted: 26 September 2018

Published online: 03 October 2018

\section{References}

1. Ferlay J, Soerjomataram I, Dikshit R, Eser S, Mathers C, Rebelo M, Parkin DM, Forman D, Bray F. Cancer incidence and mortality worldwide: sources, methods and major patterns in GLOBOCAN 2012. Int J Cancer. 2015;136(5): E359-86.

2. Chen W, Zheng R, Zhang S, Zeng H, Xia C, Zuo T, Yang Z, Zou X, He J. Cancer incidence and mortality in China, 2013. Cancer Lett. 2017;401:63-71.

3. Chen W, Zheng R, Zhang S, Zeng H, Zuo T, Xia C, Yang Z, He J. Cancer incidence and mortality in China in 2013: an analysis based on urbanization level. Chin J Cancer Res. 2017;29(1):1-10.

4. Ma YT, Lian SY, Liu ZC, Cheng LP, Li BY, Quan PL, Lu JB, Sun XB. Period survival analysis of esophageal cancer in Linzhou city of Henan province. Zhonghua Yu Fang Yi Xue Za Zhi. 2009;43(12):1100-4.

5. Liu SZ, Yu L, Chen Q, Quan PL, Cao XQ, Sun XB. Incidence and survival of esophageal cancer with different histological types in Linzhou between 2003 and 2012. Zhonghua Yu Fang Yi Xue Za Zhi. 2017;51(5):393-7.

6. Zeng H, Zheng R, Guo Y, Zhang S, Zou X, Wang N, Zhang L, Tang J, Chen J, Wei K, et al. Cancer survival in China, 2003-2005: a population-based study. Int J Cancer. 2015;136(8):1921-30.

7. Dickman PW, Adami HO. Interpreting trends in cancer patient survival. J Intern Med. 2006:260(2):103-17.

8. Dickman PW, Sloggett A, Hills M, Hakulinen T. Regression models for relative survival. Stat Med. 2004;23(1):51-64.

9. Verdecchia A, De Angelis R, Capocaccia R, Sant M, Micheli A, Gatta G, Berrino $F$. The cure for colon cancer: results from the EUROCARE study. Int J Cancer. 1998;77(3):322-9.

10. Andersson TM, Dickman PW, Eloranta S, Lambert PC. Estimating and modelling cure in population-based cancer studies within the framework of flexible parametric survival models. BMC Med Res Methodol. 2011;11:96.

11. Royston P, Parmar MK. Flexible parametric proportional-hazards and proportional-odds models for censored survival data, with application to prognostic modelling and estimation of treatment effects. Stat Med. 2002; 21(15):2175-97.

12. Lambert PC, Thompson JR, Weston $\mathrm{CL}$, Dickman PW. Estimating and modeling the cure fraction in population-based cancer survival analysis. Biostatistics. 2007:8(3):576-94.

13. Nelson CP, Lambert PC, Squire IB, Jones DR. Flexible parametric models for relative survival, with application in coronary heart disease. Stat Med. 2007; 26(30):5486-98

14. De Angelis R, Capocaccia R, Hakulinen T, Soderman B, Verdecchia A. Mixture models for cancer survival analysis: application to population-based data with covariates. Stat Med. 1999;18(4):441-54.

15. Durrleman S, Simon R. Flexible regression models with cubic splines. Stat Med. 1989;8(5):551-61.
16. Ederer $F$, Heise $H$. Instructions to IBM 650 programmers in processing survival computations: methodological note no 10. Bethesda: National Cancer Institute; 1959

17. Andersson TML, Lambert PC. Fitting and modeling cure in populationbased cancer studies within the framework of flexible parametric survival models. Stata J. 2012;12(4):623-38.

18. Lambert PC, Dickman PW, Osterlund P, Andersson T, Sankila R, Glimelius B. Temporal trends in the proportion cured for cancer of the colon and rectum: a population-based study using data from the Finnish Cancer registry. Int J Cancer. 2007;121(9):2052-9.

19. liu ZC, Lian SY, Li BY. An analysis of gastric cardiac/esophageal lesions diagnosed by endoscope examination in esophageal cancer high risk area in Linzhou. China Cancer. 2014;23(2):124-7.

20. Guan $C T$, Song GH, Li BY, Gong YW, Hao CQ, Xue LY, Chen WQ, Wei WQ. Endoscopy screening effect on stage distributions of esophageal cancer: a cluster randomized cohort study in China. Cancer Sci. 2018;109(6):1995-2002.

21. Liu SZ, Yu L, Li BY, Hao CQ, Wang JW, Cao XQ, Sun XB. Analysis survival of screening and non-screening patients of esophageal cancer in Linzhou city. Zhonghua Yu Fang Yi Xue Za Zhi. 2018;52(3):238-42.

22. Lambert PC, Dickman PW, Weston CL, Thompson JR. Estimating the cure fraction in population-based cancer studies by using finite mixture models. J R Stat Soc: Ser C: Appl Stat. 2010;59(1):35-55.

\section{Ready to submit your research? Choose BMC and benefit from:}

- fast, convenient online submission

- thorough peer review by experienced researchers in your field

- rapid publication on acceptance

- support for research data, including large and complex data types

- gold Open Access which fosters wider collaboration and increased citations

- maximum visibility for your research: over $100 \mathrm{M}$ website views per year

At BMC, research is always in progress.

Learn more biomedcentral.com/submissions 